\title{
Bacteriological Profile of Endotracheal Aspirates and their Antibiotic Susceptibility Pattern
}

\author{
Ranjitha Shankare Gowda, Sowmya G.S. *, Pavithra N., Raghavendra Rao M., \\ Krishna Karthik M. and Satya Sai B. \\ Department of Microbiology, JSS Medical College, JSSAHER, Mysore - 570 015, India.
}

\begin{abstract}
Early onset Ventilator associated pneumonia (VAP) is usually less severe, associated with a better prognosis, and is more likely caused by antibiotic- sensitive bacteria. Late-onset VAP, is usually caused by multidrug resistant (MDR) pathogens and is associated with increased morbidity and mortality. Therefore, the local microbial flora causing VAP needs to be studied and appropriate therapy based on the early endotracheal (ET) aspirate culture report can help managing this group of patients. The present study was carried out in the department of Microbiology, JSS Hospital, Mysore from January 2017 to December 2017. Bacterial pathogens and antibiotic resistance pattern of isolates from ET aspirates of patients on mechanical ventilation in Intensive care units were source of data. A total number of 1432 samples were received in the lab for ET aspirate culture. Among these 1432 samples, 1055 showed growth ranging from $10^{2}$ to $10^{6}$ colony forming units $/ \mathrm{ml}$ (CFU/ml), 124 had no growth at all and 253 had no significant growth $\left(<10^{2} \mathrm{CFU} / \mathrm{ml}\right)$ Out of 1055 isolates,1023 were Gram negative bacteria and 32 were Gram positive cocci . Acinetobacter, Pseudomonas and Klebsiella were the major pathogens in our study. Majority of them being MDR, maximum sensitivity was observed for Tigecycline and colistin in these isolates. Knowledge of causative microbial flora of VAP along with information on the susceptibility patterns will help in selection of the appropriate antibiotic for therapeutic use for better outcome.
\end{abstract}

Keywords: VAP, ET aspirates, Early onset, MDR, susceptibility pattern.

*Correspondence: sowmyashivappa@gmail.com; +91-9886686854

(Received: 15 August 2018; accepted: 09 October 2018)

Citation: Ranjitha Shankare Gowda, Sowmya G.S., Pavithra N., Raghavendra Rao M., Krishna Karthik M. and Satya Sai B., Bacteriological Profile of Endotracheal Aspirates and their Antibiotic Susceptibility Pattern, J Pure Appl Microbiol., 2018; 12(4): 2283-2287. http://dx.doi.org/10.22207/JPAM.12.4.69

(c) The Author(s) 2018. Open Access. This article is distributed under the terms of the Creative Commons Attribution 4.0 International License which permits unrestricted use, sharing, distribution, and reproduction in any medium, provided you give appropriate credit to the original author(s) and the source, provide a link to the Creative Commons license, and indicate if changes were made. 


\section{INTRODUCTION}

Ventilator associated pneumonia (VAP) is a globally known notorious nosocomial infection that occurs more than 48 hours after a patient begins mechanical ventilation (MV)making recovery more difficult for patients who are already critically ill. ${ }^{1}$ Early onset VAP is usually less severe, associated with a better prognosis, and is more likely to be caused by antibiotic- sensitive bacteria. Late-onset VAP, is usually caused by multidrug resistant (MDR) pathogens and is associated with increased morbidity and mortality ${ }^{2,3}$. VAP results from microaspiration, which is primary route of bacterial entry into respiratory tract. The ET tube acts as an obstacle to host defences by inhibiting the action of cilia, swallowing, and spontaneous coughing by the patients. Risk factors that are associated with increased incidence of VAP are body position, state of consciousness, enteral nutrition, prior exposure to antibiotics, use of a nasotracheal tube and pre-existing conditions such as acute respiratory distress syndrome ${ }^{4}$.

Typically, diagnosis includes clinical, radiologic and microbiologic evidence of infection. However, the exact criteria for diagnosis varies widely among institutions and thus results in a wide range of reported VAP mortality rates, which is stated to be anywhere from $0-76 \%^{5,6,7}$. Many studies from India have investigated the causative organisms of VAP. Pseudomonas species, Acinetobacter species, Escherichia coli, Klebsiella pneumoniae and Staphylococcus aureus are the common pathogens with varying prevalence and quite often being MDR ${ }^{6,8,9}$. Therefore, the local microbial flora causing VAP needs to be studied and an appropriate therapy based on the early ET aspirate report can reduce the mortality and cost in managing this group of patients

Aim

In view of increasing incidence of VAP and MDR nature of pathogens in our hospital, this study was taken up to detect the bacteriological profile and sensitivity pattern of isolates from Endotracheal aspirates

\section{MATERIALS AND METHODS}

The present study was carried out in the Department of Microbiology, JSS Hospital, Mysore, Karnataka, for a period of 1 year from January 2017 to December 2017. This was a prospective study. ET aspirates sent from various intensive care units sent to Microbiology laboratory formed the material of our study

\section{Bacterial identification and isolation}

The ET samples received in the Microbiology lab were subjected to microscopy and culture. Gram stain of Lower respiratory tract secretions is an immediate procedure that can guide management and it has a reasonable correlation with culture results Semiquantitative culture was done on blood agar and MacConkey agar and incubated overnight at $37^{\circ} \mathrm{C}$ for 24 to $48 \mathrm{hrs}$ for bacterial growth and isolation. The isolated organisms were processed with Vitek 2 systems for identification as well as Antibiotic susceptibility testing. Colony count of $10^{6} \mathrm{CFUml}$

Table 1. Distribution of microbial isolates in colony forming units per $\mathrm{ml}$

\begin{tabular}{lccccc}
\hline & $10^{2}$ & $10^{3}$ & $10^{4}$ & $10^{5}$ & $10^{6}$ or more \\
\hline Acinetobacter & 26 & 57 & 23 & 192 & 130 \\
Klebsiella & 19 & 32 & 20 & 136 & 77 \\
Pseudomonas & 10 & 27 & 9 & 117 & 62 \\
E.coli & 2 & 2 & 2 & 12 & 11 \\
Proteus & 0 & 0 & 0 & 0 & 3 \\
Citrobacter & 0 & 3 & 1 & 2 & 0 \\
Enterobacter & 0 & 0 & 2 & 3 & 1 \\
Serratia & 2 & 1 & 2 & 10 & 5 \\
Stenotrophomonas & 1 & 2 & 4 & 4 & 3 \\
Burkholderia & 0 & 0 & 0 & 3 & 3 \\
Morganella & 0 & 1 & 0 & 0 & 1 \\
S.aureus & 0 & 0 & 8 & 13 & 4 \\
Coagulase negative Staphylococcus & 2 & 5 & 0 & 0 & 0 \\
\hline \hline Journal of Pure and Applied Microbiology & \multicolumn{7}{c}{2284} & & & www.microbiologyjournal.org
\end{tabular}


or more was considered significant for VAP . ET aspirates yielding growth between $10^{2 \text { to }} 10^{6} \mathrm{CFU} /$ $\mathrm{ml}$, whose microscopy revealed moderate to plenty of inflammatory cells were also processed.

\section{RESULTS}

A total number of 1432 samples were received in the lab for ET aspirate culture. Among these 1432 samples, 1055 showed growth ranging from $10^{2}$ to $10^{6} \mathrm{CFU} / \mathrm{ml}$ or more, 124 had no growth at all and 253 had no significant growth $\left(<10^{2} \mathrm{CFU} / \mathrm{ml}\right)$ Among 1055 bacterial growth isolates, 377 isolates showed growth $10{ }^{6} \mathrm{CFUml}$ or more which is considered significant for VAP and 731 isolates ranging $10^{2}$ to $10^{6} \mathrm{CFU} / \mathrm{ml}$.

Out of 1055 isolates, 1023 were Gram negative bacteria and 32 were Gram positive cocci. Out of 1023 GNB, 428 were Acinetobacter species,284 were Klebsiella species,225 were Pseudomonas species, 29 were E.coli, 3 Proteus spp, 6 Citrobacter spp, 6 Enterobacter spp, 20 Serratia, 14 Stenotrophomonas, 6 Burkholderia spp and 2 Morganella spp. Acinetobacter baumanii, Klebsiella pneumoniae and Pseudomonas aeruginosa were the most common isolates in our study. Amongst the 32 gram positive isolates

Table 2. Antibiotic Resistance pattern of Acinetobacter

\begin{tabular}{llll}
\hline Antibiotics & Sensitive & Intermediate & Resistant \\
\hline Piperacillin/Tazobactum & $33(7 \%)$ & $3(0.7 \%)$ & $392(92 \%)$ \\
Ceftazidine & $18(4 \%)$ & $20(4.6 \%)$ & $390(92 \%)$ \\
Cefoperazone/ Sulbactum & $100(23 \%)$ & $66(15 \%)$ & $262(62 \%)$ \\
Cefepime & $31(7.2 \%)$ & $14(3.2 \%)$ & $383(89.4 \%)$ \\
Aztreonam & $10(2.0 \%)$ & $5(1.16 \%)$ & $413(95 \%)$ \\
Doripenem & $37(8.64 \%)$ & & $391(92 \%)$ \\
Imipenem & $34(7.94 \%)$ & $8(1.86 \%)$ & $386(90.1 \%)$ \\
Meropenem & $39(9.11 \%)$ & $8(1.86 \%)$ & $381(89.01 \%)$ \\
Amikacin & $17(3.97 \%)$ & $1(0.23 \%)$ & $410(95.79 \%)$ \\
Gentamicin & $78(18.22 \%)$ & $32(7.4 \%)$ & $318(74 \%)$ \\
Ciprofloxacin & $30(7.9 \%)$ & $12(2.80 \%)$ & $386(90 \%)$ \\
Levofloxacin & $32(7.4 \%)$ & $52(12.14 \%)$ & $344(80.3 \%)$ \\
Minocycline & $242(56.54 \%)$ & $46(10.74 \%)$ & $140(32.7 \%)$ \\
Tigecycline & $346(80.84 \%)$ & $75(17.52 \%)$ & $7(1.63 \%)$ \\
Colistin & $412(96.26 \%)$ & & $16(3.7 \%)$ \\
Cotrimoxazole & $69(16.12 \%)$ & & $359(84 \%)$ \\
\hline
\end{tabular}

Table 3. showing Antibiotic resistance pattern of Pseudomonas

\begin{tabular}{llll}
\hline Antibiotics & Sensitive & Intermediate & Resistant \\
\hline Ticarcillin/Clavulinic acid & $72(32 \%)$ & $59(26.22 \%)$ & $94(42.22 \%)$ \\
Piperacillin/Tazobactum & $110(48.88 \%)$ & $25(11.11 \%)$ & $90(40 \%)$ \\
Ceftazidine & $125(55.55 \%)$ & $20(8.88 \%)$ & $80(35.55 \%)$ \\
Cefoperazone/ Sulbactum & $127(56.44 \%)$ & $49(21.77 \%)$ & $49(21.77 \%)$ \\
Cefepime & $119(52.8 \%)$ & $20(8.88 \%)$ & $86(38.22 \%)$ \\
Aztreonam & $81(36 \%)$ & $59(26.22 \%)$ & $85(37.77 \%)$ \\
Doripenem & $132(58.66 \%)$ & $3(1.33 \%)$ & $90(40 \%)$ \\
Imipenem & $136(60.4 \%)$ & $0(0 \%)$ & $89(39.5 \%)$ \\
Meropenem & $126(56 \%)$ & $13(5.7 \%)$ & $86(38.22 \%)$ \\
Amikacin & $150(66.6 \%)$ & $71(31.5 \%)$ & $4(1.7 \%)$ \\
Gentamicin & $119(52.88 \%)$ & $3(1.33 \%)$ & $32(14.22 \%)$ \\
Ciprofloxacin & $118(52.44 \%)$ & $13(5.77 \%)$ & $94(41.77 \%)$ \\
Levofloxacin & $121(53.77 \%)$ & $9(4 \%)$ & $95(42.22 \%)$ \\
Colistin & $206(91.55 \%)$ & $2(0.8 \%)$ & $17(7.55 \%)$ \\
\hline
\end{tabular}


25 were Staphylococcus aureus, 3 Streptococcus pneumoniae, 2 Beta hemolytic Streptococci and 2 coagulase negative Staphylococcus.

Majority of Enterobacteriaceae apart from Klebsiella isolates were sensitive to
Imipenem, Ertapenem, Meropenem, Gentamicin, Amikacin, Tigecycline, Colistin, Cotrimoxazole, Ampicillin. Among the 25 Staphylococcus aureus, 4 were Methicillin resistant Staphylococcus aureus sensitive Vancomycin and Linezolid.

Table 4. Antibiotic resistance pattern of Klebsiella

\begin{tabular}{llll}
\hline Antibiotics & Sensitive & Intermediate & Resistant \\
\hline Amoxyclav & $41(14.43 \%)$ & $44(15.49 \%)$ & $199(70.07 \%)$ \\
Piperacillin/Tazobactum & $48(16.9 \%)$ & $10(3.5 \%)$ & $226(79.5 \%)$ \\
Cefuroxime & $43(15 \%)$ & $6(2.11 \%)$ & $235(82.7 \%)$ \\
Cefuroxime axetil & $48(16.9 \%)$ & $5(1.76 \%)$ & $231(81.3 \%)$ \\
Cefoperazone/ Sulbactum & $77(21 \%)$ & $3(1 \%)$ & $204(71.83 \%)$ \\
Cefipime & $49(17 \%)$ & $13(4.57 \%)$ & $222(78.3 \%)$ \\
Ertapenem & $98(34.5 \%)$ & $13(4.57 \%)$ & $173(60.91 \%)$ \\
Nalidixic acid & $74(26.05 \%)$ & $16(5.63 \%)$ & $194(68 \%)$ \\
Imipenem & $119(41.90 \%)$ & $63(22.18 \%)$ & $102(35.91 \%)$ \\
Meropenem & $84(29.57 \%)$ & $10(3.52 \%)$ & $190(66.90 \%)$ \\
Amikacin & $169(59.5 \%)$ & $40(14.08 \%)$ & $75(26.40 \%)$ \\
Gentamicin & $120(42.2 \%)$ & $6(2.11 \%)$ & $158(55.63 \%)$ \\
Ciprofloxacin & $83(29.22 \%)$ & $24(8.45 \%)$ & $177(62.32 \%)$ \\
Tigecycline & $180(63.3 \%)$ & $64(22.53 \%)$ & $40(14 \%)$ \\
Colistin & $270(95 \%)$ & $1(0.35 \%)$ & $13(4.57 \%)$ \\
Cotrimaxozole & $102(35.9 \%)$ & $2(0.70 \%)$ & $180(63.38 \%)$ \\
Ceftriaxone & $40(14.08 \%)$ & $2(0.70 \%)$ & $242(85.21 \%)$ \\
\hline
\end{tabular}

Table 5. Range of Values of MIC of Tigecycline and Colistin for most frequent MDR isolates.

\begin{tabular}{lcccccc}
\hline Oraganisms & $\begin{array}{c}\text { Sensitive } \\
\leq 0.5-2\end{array}$ & $\begin{array}{c}\text { Tigecycline } \\
\text { Intermediate } \\
>2-6\end{array}$ & $\begin{array}{c}\text { Resistant } \\
>8-16\end{array}$ & $\begin{array}{c}\text { Sensitive } \\
\leq 0.5-2\end{array}$ & $\begin{array}{c}\text { Colistin } \\
\text { Intermediate } \\
>2-6\end{array}$ & $\begin{array}{c}\text { Resistant } \\
>8-16\end{array}$ \\
\hline $\begin{array}{l}\text { Acinetobacter } \\
\text { Klebsiella }\end{array}$ & 346 & 75 & 7 & 412 & 0 & 16 \\
Pseudomonas & 180 & 64 & 40 & 270 & 1 & 13 \\
\hline
\end{tabular}

\section{DISCUSSION}

Prompt identification of organisms from ET aspirates in ventilated patients and accurate selection of antimicrobial agents, based on MIC represent important clinical goals in prevention of VAP. Sound knowledge of susceptibility pattern of the locally prevalent pathogens is necessary for choosing the appropriate antibiotics.

In our study, overall, Gram-negative bacilli predominated over Gram-positive cocci. Acinetobacter spp, Klebsiella spp followed by Pseudomonas were the most common isolates identified. Other significant Gram negative isolates were E.coli, Serratia, Stenotrophomonas, Enterobacter, Citrobacter, Proteus and Burkholderia. Among Gram positive organisms Staphylococcus aureus was most common. The antibiogram pattern of isolates showed that Maximum resistance of Acinetobacter spp and Pseudomonas were seen in Aztreonam, Cefipime, Doripenem, Imipenem, Ciprofloxacin, Piperacillin/ Tazobactum. Maximum sensitivity was observed with Colistin, Tigecycline and Minocycline. Our findings were similar to the other studies ${ }^{6,7,8,9}$

In last two decades, Gram negative bacteria have become important nosocomial 
pathogens throughout the world and is a leading problem in treatment owing to its multidrug resistance. Colistin, which is an old antimicrobial agent, is very active against these. Susceptibility to Colistin was reported as $97.9-100 \%$ in various studies. There was least resistance to Colistin in our study. It appeared to be a good option apart from Tigecycline, in the treatment of VAP developed with MDR pathogens.

\section{CONCLUSION}

We conclude that VAP in mechanically ventilated patients is on rise and has been continually associated with indiscriminate and irrational use of antibiotics which contribute to emergence of drug resistant strains. Knowledge of their causative microbial flora in a local setting along with information on the susceptibility patterns will help in selection of the appropriate antibiotic for therapeutic use and a better outcome. It is clear that Tigecycline and Colistin become the last resort antibiotics in most cases. Within no time in future, we can expect resistance to these antibiotics also making us reach the dead end. Hence, resistance rates should be pursued closely. Newer alternative drugs revealing promising results to solve the problem is the need of the hour.

\section{REFERENCES}

1. Joseph NM, Sistla S, Dutta TK, Badhe AS, Parija SC. Ventilator-associated pneumonia in a tertiary care hospital in India: Incidence and risk factors. J Infect Dev Ctries. 2009; 3:771-7.

2. Andrew A, Quartin, Ernesto G, Scerpella, Sailaja Puttagunta and Daniel H Kett. A comparison of microbiology and demographics among patients with healthcare-associated, hospitalacquired, and ventilator-associated pneumonia: a retrospective analysis of 1184 patients from a large, international study

3. Chastre J, Fagon JY. Ventilator-associated pneumonia. Am J Respir Crit Care Med. 2002; 165: 867-903.

4. Niederman MS, Craven DE. Guidelines for the management of adults with hospital-acquired, ventilator-associated, and healthcare-associated pneumonia. Am J Respir Crit Care Med. 2005; 171:388-416.

5. Afshari A, Pagani L, Harbarth S.Year in review 2011: Critical care - infection. Crit Care 2012, 16:242-247.

6. Trupti D. Satpute, Sunanda N. Shrikande. Bacteriological study of ventilator associated pneumonia in a tertiary care hospital. Int. J. Adv. Res. 6(2), 1770-1774

7. Girish N, Rajendran R.Bacteriological Profile of Ventilator Associated Pneumonia in a Tertiary Care Hospital and their Antibiotic Resistance Pattern . International Journal of Medical Microbiology and Tropical Diseases, OctoberDecember, 2015; 1(1):1-5

8. Amit Khelgi, A.G. Prathab. Bacteriological Profile of Ventilator Associated Pneumonia in a Tertiary Care Hospital of South India with Special Reference to Multi Drug Resistant Pathogens. Int.J. Curr. Microbiol. App. Sci. 2017; 6(11): 541548

9. Riddhi Pradhan, Suman Singh, Chirag Modi, Sarita Nayak, Vidit Khandelwal. Ventilator associated pneumonia in intensive care units of a tertiary care centre of Gujarat. International Journal of Medical Microbiology and Tropical Diseases, July-September, 2016; 2(3):90-93

10. Torres A, Ferrer M, Badia JR. Treatment guidelines and outcomes of hospital-acquired and ventilator-associated pneumonia. Clin Infect Dis. 2010; 51(Suppl 1):S48-53.

11. Skrupky LP, McConnell K, Dallas J, Kollef MH. A comparison of ventilator associated pneumonia rates as identified according to the National Healthcare Safety Network and American College of Chest Physicians Criteria. Crit Care Med 2012, 40:281-284.

12. Bárbara Borgatta, Jordi Rello.How to approach and treat VAP in ICU patients. BMC Infectious

13. Linden PK, Paterson DL. Parenteral and inhaled colistin for treatment of ventilatorassociated pneumonia. Clin Infect Dis. 2006; 43(Suppl.2):S89-94. Diseases 2014, 14:211

14. Jones RN. Microbial etiologies of hospitalacquired bacterial pneumonia and ventilator associated bacterial pneumonia. Clin Infect Dis. 2010; 51 (Suppl) 1:S81-7 